\title{
LOS DEBERES POSITIVOS GENERALES Y SU FUNDAMENTACIÓN
}

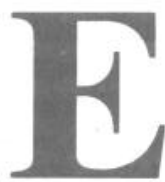

$\mathrm{n}$ los últimos años, los problemas éticos vinculados con los deberes positivos generales -principalmente por lo que respecta a su fundamentación, contenido y rango moral- han adquirido una notoria relevancia no sólo teórica sino práctica en conexión sobre todo con los derechos que confiere el artículo 25 de la Declaración Universal de los Derechos Humanos y su implementación en vista de cuestiones tan graves como la lucha contra el hambre. Deberes positivos generales son aquéllos cuyo contenido es una acción de asistencia al prójimo que requiere un sacrificio trivial y cuya existencia no depende de la identidad del obligado ni de la del (o de los) destinatario(s) y tampoco es el resultado de algún tipo de relación contractual previa. En lo que sigue me propongo, primero, exponer algunos argumentos formulados en contra de la aceptación de los deberes positivos generales y su posible equiparación a los deberes negativos generales (I). En segundo lugar, aduciré que las mismas razones que suelen invocarse para la fundamentación de los deberes negativos generales valen también para los deberes positivos generales, de manera tal que sería contradictorio aceptar los primeros y rechazar los segundos (II). Por último, espero poder mostrar que los deberes negativos generales tienen que ser complementados con los deberes positivos generales a fin de que un sistema de ética normativa pueda cumplir las funciones pragmáticas que de él se esperan (III).

\section{I}

Cinco me parecen ser los argumentos más importantes en contra de la aceptación de los deberes positivos generales:

1) En sentido estricto, no puede hablarse de deberes positivos generales. Los deberes genuinos están caracterizados por dos notas esenciales: a) su incumplimiento perjudica a los destinatarios de los mismos y b) estos últimos tienen derecho a exigir su cumplimiento. En el caso de los llamados «deberes positivos generales», la situación es justo la inversa: a) su cumplimiento beneficia y b) nadie tiene derecho a exigir su cumplimiento. Por eso, mientras los dos primeros son deberes perfectos, los segundos son deberes imperfectos. Esta tesis fue ya sustentada en el siglo XIX por John Stuart Mill y ha sido reactualizada entre otros por Jeffrie G. Murphy $(1979,17)$ :

«Si Jones está en una situación de penuria (suponiendo que yo no lo haya colocado en ella) y puedo ayudarlo sin un sacrificio extraordinario, ciertamente él querrá que lo ayude y haría algo malo si no lo ayudo. Pero él no tiene un derecho a esperar mi ayuda, no es dañado (wronged) si no lo ayudo y no sería razonable esperar que el Estado o alguien me coaccionara para que lo ayudase. Ayudarlo es una beneficencia y (a diferencia de la justicia) es una demanda moral comparativamente débil». (Subrayado de J.G.M.)

2) Si los deberes positivos generales fueran deberes perfectos, el deber de ayudar a quien padece hambre, por ejemplo, daría lugar a un derecho 
genuino que, en tanto tal, podría ser hecho valer por todo ser humano frente a los demás individuos, organizaciones y gobiernos. El ejercicio de este derecho tropezaría, por lo pronto, con dificultades empíricas debido a la escasez de recursos: el deber positivo general de ayuda a los millones de seres que padecen hambre es de cumplimiento imposible y por lo tanto no constituye deber alguno. Ésta es la tesis sostenida por la «ética del bote salvavidas», representada entre otros por Garret Hardin (1976) y Joseph Fletcher (1976).

Pero, además, en caso de que estos recursos existieran, el pretendido deber implicaría una fatal duplicación de esfuerzos y terminaría conduciendo al caos. Como lo ha señalado Carl Wellman $(1982,160)$, esto no sucede en el caso de los deberes negativos generales:

«Y tampoco surge una duplicación absurda por el hecho de que el derecho de cada individuo a no ser muerto valga con respecto a todo el mundo. El hecho de que muchos, quizás todos menos uno, se abstengan de matar aun individuo no vuelve redundante la acción de algún otro individuo adicional o de una organización o del Estado de abstenerse de privarlo de su vida. Por el contrario, la vida del individuo se salva sólo si todo el mundo... cumple con su deber de no privar de la vida al derecho habiente.»

Ésta es la «tesis de la asimetría» entre los deberes negativos generales y los deberes positivos generales.

3) Los deberes positivos generales no pueden nunca ser colocados en un pie de igualdad con los deberes negativos generales ya que el no cumplimiento de aquéllos por parte del supuesto obligado deja siempre abierta la posibilidad de que algún otro lo cumpla, evitándose así el posible mal. En cambio, la violación de un deber negativo implica lógicamente un mal: a él justamente se recurre para definir la acción que constituye el contenido del deber. Ésta es la «tesis de la opcionalidad». En palabras de Richard L. Trammell $(1975,135)$ :

«Existe una equivalencia lógica entre el no cumplimiento por parte de $y$ del deber de no causar un sufrimiento a $x$ en el tiempo $z$ y la probabilidad 1 de que $x$ sufra en el tiempo $z$; mientras que no existe una equivalencia lógica entre el no cumplimiento por parte dey del deber positivo de evitar que $x$ sufra en el tiempo $z$ y la probabilidad 1 de que $x$ sufra en el tiempo $z$. Si $y$ mata a $x$, es seguro que $x$ no vivirá, pero si $y$ deja de salvar a $x$, algún otro puede tener la opción de salvar a $y$ ».

4) Aun cuando se admita que quien se encuentra en situación de penuria tiene derecho a reclamar ayuda de extraños, es decir, exigir el cumplimiento de un deber positivo general, si el número de los necesitados es muy grande, también en el caso en que los obligados se comporten como samaritanos «mínimamente decentes», se produce un «dilema inevitable» (James S. Fishkin 1982, 169).

En efecto, es imposible mantener la «estructura básica de la moral individual» -caracterizada por la división de los actos humanos en indiferentes, supermeritorios y obligatorios; por el límite del heroísmo y por una amplia zona de comportamientos moralmente indiferentes (Fishkin 1982,33)y al mismo tiempo sostener la vigencia de deberes positivos generales. Si se los acepta, sea en la versión débil de la premisa normativa de Peter Singer (1979, 168 ss.), en la del altruismo limitado de James S. Fishkin (1982) o 
del sacrificio trivial de John D. Hodson (1983, 60 s.), como, por ejemplo, dar 100 pesetas para contribuir a la lucha contra el hambre en el mundo es siempre un sacrificio trivial, una vez que hayamos dado 100 pesetas dar otras 100 también será un sacrificio trivial. Pero la reiteración de estos sacrificios insignificantes irá eliminando poco a poco la barrera del heroísmo y disminuyendo consecuentemente la zona de los comportamientos indiferentes desde el punto de vista moral y se derrumbará la estructura básica de la moral individual. Pensar que el cumplimiento reiterado de un deber positivo no altera la calidad moral del acto que constituye su contenido (y lo transforma de obligatorio en supermeritorio) es lo mismo que creer que no existe la paradoja del grano y del montón o que la pérdida reiterada de un pelo tras otro no conduce a la calvicie. Por otra parte, renunciar a la vigencia de los deberes positivos generales significa abandonar principios básicos de la moral y hasta lo que suele llamarse «punto de vista moral». En la formulación de James S. Fishkin (1982, 153):

«O bien tengo que renunciar a algún elemento de la estructura básica de la moral individual o tengo que renunciar a las obligaciones generales. En caso contrario, hay que aceptar el derrumbe de nuestras suposiciones fundamentales. Tal derrumbe significaría que carecemos de una coherente posición moral. Estimularía el cinismo y la hipocresía.»

Tal es el «dilema de Fishkin».

5) La solución del dilema de Fishkin no podría eliminar una diferencia básica que existe entre los deberes negativos y los positivos: los primeros prohiben acciones; los segundos, omisiones.

Una acción reprochable, se dice, revela una intención malévola, mientras que la omisión es, por lo general, la consecuencia de una actitud apática. No es lo mismo, por ejemplo, enviar comida envenenada a la India que no contribuir a una colecta contra el hambre en ese país. En el primer caso, quien así actúa desea la muerte de un determinado número de personas; en el segundo, se trata tan sólo de un apático indiferente que, por cierto, no desea el mal a nadie (cfr. Raymond A. Belliotti 1984, 84).

Es siempre peor ser la causa de un daño que dejar que sigan existiendo circunstancias perniciosas. En el primer caso, la víctima no hubiera sufrido el daño si el agente no hubiera existido; en cambio, esto no vale para el segundo caso. En esta variante de la «tesis de la opcionalidad», se afirma que la acción es «más causa» que la omisión (cfr. Ted Honderich 1980, 67). La acción completa la circunstancia causal y vuelve necesario el resultado. Es moralmente peor iniciar la cadena causal que provoca la muerte de una persona que no interrumpir la cadena causal que conduce a la muerte. La noción de causalidad es utilizada aquí para imputar mayor responsabilidad moral al agente de la acción que al de la omisión (cfr. Trammell 1976).

Mientras que podemos vivir sin realizar acciones prohibidas, es difícil hacerlo sin omitir muchas veces lo supuestamente debido, por ejemplo, sin salvar todas las vidas que podríamos haber salvado de morir de hambre (cfr. Peter Singer 1979, 163). Las acciones requieren tiempo para su realización; por ello, la lista de las acciones que podemos realizar es siempre finita. En cambio, las omisiones, como no requieren tiempo, son infinitas (cfr. Jonathan Glover 1977, 104). 
Los efectos colaterales de una acción moralmente reprochable suelen ser peores que los de la omisión. La acción de matar provoca, por lo general, mayor inseguridad e incertidumbre en la comunidad a la que pertenece la víctima y el criminal que la muerte por omisión (cfr. Glover 1977, 99 y Ted Honderich 1980, 78 s.).

Por último, para que pueda hablarse de omisión es necesario que existan ciertas expectativas deónticas o empíricas, lo que reduce enormemente el campo de las omisiones y vuelve imposible una equiparación entre deberes positivos generales y deberes $\underset{*}{\operatorname{siv}}$ gativos generales.

Veamos más de cerca estos argumentos.

1') En el primero de ellos, los conceptos de daño y beneficio juegan un papel fundamental para la distinción entre deberes negativos y positivos. El cumplimiento de un deber positivo es entendido como un beneficio, como un plus gratuito que colocaría a la persona auxiliada en una situación superior a la que se encontraba antes de comenzar a padecer el mal superado con la ayuda. Si esto es lo que se quiere decir con «beneficiar», la aseveración es falsa: Cuando, por ejemplo, salvo a alguien que se está ahogando no agrego un ápice a su statu quo ante al volverlo a tierra. Y por supuesto que si al negar mi ayuda impido que alguien recupere el status en el que se encontraba antes de comenzar a padecer el mal cuya superación está bajo mi control, lo he dañado. Dañar no significa únicamente empeorar una situación o transformar una situación positiva en una negativa sino también no evitar que un mal se produzca o permitir que continúe, cuando el agente pudo haberlo impedido o superado sin que ello implicara mayor sacrificio de su parte (Cfr. Alan Gewirth 1978, 224).

Por otra parte, si en el caso de los deberes positivos, se entiende por «beneficio» evitar un mal, interrumpiendo una cadena causal que conduce a un daño, también en el caso de los deberes negativos podría decirse que beneficio a alguien cuando no inicio la cadena causal que concluye en el daño de una persona o sus bienes. No existe diferencia entre el daño que causa la violación de un deber positivo y la de un deber negativo siempre que se trate de un mismo bien (por ejemplo, la vida) y se den las mismas condiciones de motivación, intención o posibilidad de actuar y de omitir.

La contraposición entre daño y beneficio es un recurso frecuente entre quienes sostienen una marcada diferencia entre deberes negativos y positivos. Si se la acepta, resulta plausible la afirmación de W. D. Ross: "Aun cuando reconozcamos el deber de beneficencia, me parece que el deber de no dañar . . . tiene que ser reconocido como más obligatorio prima facie ... » $(1963,22)$. Pero lo que sucede es que la contraposición es falsa. La negación interna (es decir, en sentido fuerte) de dañar no es beneficiar sino simplemente no dañar. $\mathrm{O}$, si se quiere utilizar la terminología de Georg $\mathrm{H}$. von Wright, la negación interna de dañar es hacer lo que es necesario para la conservación de un bien:

«De nuestras definiciones de lo que es beneficioso y dañino no se sigue que si no-X es dañino, entonces $\mathrm{X}$ es beneficioso, y vice versa. $\mathrm{Si}$, sin embargo, no-X es dañino, entonces $X$ sera llamado necesario. Lo necesario es aquello cuya falta o pérdida es algo malo, un mal. Lo necesario y lo 
dañino se oponen como contradictorios, en el sentido que lo contradictorio de lo necesario es dañino y vice versa. Lo beneficioso y lo dañino se oponen como contrarios.» (1963, 108. Subrayado de G. H. von W.).

El no infringir daño no es muestra alguna de generosidad. Sería absurdo agradecer cotidianamente a quienes no nos dañan, como si ello fuera expresión de un comportamiento no obligatorio, similar a la generosidad de quienes nos benefician. Debemos en cambio agradecimiento a quienes nos benefician, es decir, a quienes nos colocan en una situación mejor a la que nos encontrábamos con anterioridad a la recepción del beneficio, siempre que ellos no sean responsables de la situación así mejorada. Si esta última condición no se da, tampoco cabe el agradecimiento. Kant, quien también admitía la distinción entre deberes perfectos e imperfectos, tenía fundadas dudas acerca de si la ayuda prestada por quienes están en condiciones de hacerlo en virtud de una injusticia previa es realmente beneficencia:

«¿Merece bajo tales circunstancias la ayuda que el rico puede prestar a quien padece penuria el nombre de beneficencia, con el cual le gusta pavonearse?» $\left(1956^{2}, 591\right)$.

Desde luego, Murphy podría aducir que cuando utiliza el participio «wronged», que aquí ha sido traducido por «dañado», lo hace para indicar que no se ha afectado ningún derecho de la persona en peligro y no en el sentido de «harm». En este caso, «no es dañado (wronged)» no sería más que otra formulación de la misma proposición expresada con el enunciado «no tiene derecho a». Es decir, no agregaría ningún argumento más a lo hasta entonces dicho. Sería una explicitación del concepto de «deber imperfecto» que Murphy parece vincular con la falta de un derecho jurídico como lo indica su referencia a la posibilidad de coacción estatal. La distinción entre «wrong»y «harm» puede ser útil para la interpretación de ficciones jurídicas como la expresada en la máxima «Volenti non fit injuria» (cfr. al respecto Joel Feinberg $1983^{2}, 4$ s.) pero no para la discusión moral, a menos que se quiera argumentar circularmente y decir que no se daña (en el sentido de «wrong») cuando no se salva a alguien que solicita una ayuda que puede ser prestada sin mayor sacrificio porque no existe el derecho moral a solicitarla y que la prueba de que no existe este derecho es que la persona a quien se le niega la ayuda no ha sido dañada porque no existe el derecho moral a solicitarla.

Si se quiere conservar la distinción entre deberes perfectos e imperfectos, quizás sea más adecuado, como lo ha señalado Joel Feinberg $(1983,105)$, recurrir a otra de las versiones mencionadas por Mill al referirse a los deberes imperfectos. Este concepto se aplicaría a aquellos casos en los que «a pesar de que el acto es obligatorio, las ocasiones particulares de su realización quedan libradas a nuestra elección» $(1962,305)$. En este caso, sostiene Feinberg, ninguno de los posibles destinatarios del deber de ayudar tiene un derecho específico a exigir mi ayuda; el «deber es 'imperfecto' por falta de receptores determinados con derechos correlativos...» $(1983,105$ s.). Pero el hecho de que este deber sea imperfecto no significa que ayudar a quienes se pueda sea una «demanda moral comparativamente débil» como afirma Murphy. La indeterminación del destinatario del deber no afecta la fuerza moral del mismo. Esto vale no sólo para los deberes positivos generales sino también para los especiales: el bañero que ve que varias personas se están 
ahogando y no puede salvarlas a todas tiene el deber positivo especial (profesional) de salvar a todas las que pueda aunque no sea a una determinada. Y sería realmente extraño que el bañero adujera que en este caso ha realizado un acto de beneficencia con respecto a las personas que salvó y que nadie podría haberlo obligado a realizar la acción de salvamento porque los destinatarios eran indeterminados.

Utilizar el concepto de deber imperfecto para establecer una distinción de calidad moral entre los deberes negativos y los positivos (sean éstos especiales o generales) no parece ser una buena vía.

2') Carl Wellman estaría dispuesto a aceptar que con respecto a la vida y la seguridad rigen tanto los deberes negativos como los positivos. En cambio esto no valdría para el caso en que de lo que se trata es de prestar ayuda para asegurar la subsistencia. Joseph Collins-Francis Moore Lappé (1971) y Amartya Sen (1982) han puesto de manifiesto que el problema del hambre en el mundo no es una cuestión de disminución de las disponibilidades alimenticias, como afirman quienes propician la «ética del bote salvavidas» sino de lo que Sen llama «Entitlement Exchange», es decir, la posibilidad de acceso al mercado de alimentos por parte de ciertos grupos de la población de un país. Se trata justamente de un problema de ética jurídicopolítica, vinculada con la distribución de la propiedad, y no de falta de alimentos. La premisa empírica del argumento en contra de los deberes positivos generales es pues falsa.

Cuando se aduce que el cumplimiento de deberes positivos generales conduce a la duplicación de esfuerzos, se olvida una característica propia de los deberes positivos generales, sobre todo en el caso en que el número de los obligados es grande y/o también lo es el de las personas destinatarias de este deber: su cumplimiento requiere reglas para la coordinación de los esfuerzos. Robert Nozick (1974, 12 ss.), al referirse a las organizaciones protectoras en el estado de naturaleza, señala los inconvenientes que trae aparejada una asistencia no reglada. Bajo el principio «uno para todos y todos para uno», al aumentar el número de los miembros de la asociación aumenta también el costo de la contribución de cada cual hasta llegar a un límite en el que resulta imposible acudir en ayuda de todo aquel que la solicita y dedicarse al mismo tiempo a la satisfacción de las propias necesidades. La imagen de personas corriendo de un lado para otro todo el tiempo a fin de brindar ayuda a todo aquel que la requiere presenta rasgos notorios de caos e ineficiencia; no hay duda que la vida de cada uno de los miembros de esta asociación no estructurada se convertiría también en un infierno. De allí que la salida de esta situación sea el paso a asociaciones estructuradas sobre la base de la división del trabajo, es decir, también de la delimitación de responsabilidades.

Si lo que quiere decir la «tesis de la asimetría» es que criterios de equidad y de eficiencia requieren, en el caso de los deberes positivos, la división de cargas y tareas -a menos que se trate de casos individuales de peligro inminente y no previsible (como el del conocido ejemplo del niño que se ahoga)- la tesis es correcta. Pero ésta es una característica de los deberes positivos en general y no se ve por qué el inconveniente de la duplicación de esfuerzos ha de ser atribuido sólo al caso de la ayuda a la subsistencia y no también al de los deberes positivos con respecto a la vida y la seguridad. 
Sin embargo, hay algo en la argumentación de Wellman que conviene subrayar y es el haber señalado que también el derecho a la vida y a la seguridad requiere el cumplimiento de deberes positivos. Sobre este punto volveré más adelante.

3') La «tesis de la opcionalidad» no parece ser muy convincente para establecer una distinción significativa entre deberes negativos y positivos. En caso de deberes positivos no divisibles, la responsabilidad por no prestar ayuda recae por igual sobre todos los que pueden prestarla y sería realmente insólito que alguien adujera que no prestó ayuda porque quería dejar abierta a los demás la opción de hacerlo.

El 13 de marzo de 1964, se produjo en el barrio neoyorkino de Queens un hecho que ha pasado a integrar la lista de ejemplos clásicos de la literatura sobre este tipo de problemas: Kitty Genovesse fue asaltada y apuñalada frente a su domicilio. El asaltante actuó con notoria lentitud y durante unos 35 minutos los gritos de Kitty pidiendo auxilio fueron escuchados, por lo menos, por 38 residentes de casas vecinas, la mayoría de los cuales hasta vio con sus propios ojos el asesinato. Sin embargo, ninguno de ellos cogió el teléfono para avisar a la policía lo que estaba sucediendo. Si sólo uno de ellos lo hubiera hecho, es probable que el asesinato no se hubiera consumado. ¿Podría decirse que en este caso la responsabilidad moral de solicitar ayuda a la policía es con respecto a cada uno de los 38 vecinos $1 / 38$ ?

Éste es por cierto un interesante ejemplo de lo que Geoffrey Brennan y Moren Lomansky llaman «unanimidad ineficaz» (1984, 155 ss.), pero la «apatía» de cada uno de los 38 vecinos difícilmente es excusable aduciendo que cada uno de ellos quería dejar abierta a los restantes 37 la opción de prestar asistencia y que, por consiguiente, su responsabilidad moral por la omisión es menor que en el caso de que hubiera habido un único testigo.

Otro es el caso cuando se trata de obligaciones positivas divisibles (por ejemplo, contribuciones para crear un fondo de ayuda contra el hambre) o de situaciones que requieren una especialización profesional para prestar ayuda (como en el caso del médico y alguien que sufre un infarto en plena calle), la división del trabajo no tiene nada que ver con el principio de opcionalidad.

Si la «tesis de la opcionalidad» lo que quiere decir es que cuando se trata de deberes positivos generales el daño es menos probable que en el caso de los deberes negativos, lo único que cabe decir es: ¡depende de las circunstancias! También en el ejemplo del envío de carne envenenada a la India, si un empleado de Correos descubre a tiempo el contenido de la encomienda, podrá evitarse el daño, pero ello no disminuye el reproche moral que pesaría sobre el remitente.

4') Si se toman en cuanta las consideraciones formuladas con respecto a Wellman y se recoge la sugerencia del propio Fishkin (1982) en el sentido de institucionalizar el deber positivo general de prestar ayuda contra el hambre, su «dilema» puede ser solucionado si se aceptan las siguientes reglas:

a) Todo individuo está moralmente obligado a realizar un sacrificio trivial para evitar un daño o contribuir a superarlo, sin que para ello sea relevante la existencia de una relación contractual previa o la identidad de los destinatarios de la obligación. 
b) El sacrificio trivial está temporalmente delimitado, es decir, su reiteración es exigible después de haber pasado un cierto tiempo de recuperación que restituya al obligado a la situación en la que se encontraba antes de realizar el sacrificio trivial.

c) Nadie está moralmente obligado a compensar la no realización de sacrificios triviales por parte de otros miembros de su clase o comunidad, cuando se trate de deberes positivos divisibles.

d) Nadie está moralmente obligado a realizar un sacrificio trivial cuando quien lo solicita está en condiciones de superar por sí mismo su situación de penuria.

e) Los sacrificios triviales deberán ser coordinados sobre la base de la división del trabajo y la especialización.

La regla a) tiene como contenido la definición de deber positivo general.

La regla b) procura asegurar el mantenimiento de la calidad de «trivial» del sacrificio (que es justamente el presupuesto del que parte Fishkin).

En el razonamiento de Fishkin hay por lo menos dos confusiones conceptuales que conducen a su «dilema». La primera consiste en vincular sin más la nota de generalidad de una obligación con la exigencia de su cumplimiento simultáneo o reiterado sin limitación temporal alguna. La segunda, en no distinguir entre lo que los economistas llaman «cambio de escala»y «cambio de intensidad».

Es verdad que, como dice Fishkin, una obligación es general cuando «se aplica a todos los casos posibles relevantemente similares», es decir, a «una clase abierta de eventos posibles» $(1982,26)$. Pero de aquí no se infiere necesariamente que todo tipo de deber positivo general deba cumplirse simultáneamente cada vez que se presente la clase abierta de casos para los que rige. Sostener esta conclusión significa desconocer el factor tiempo, que es esencial en toda obligación positiva, sea ésta general o especial.

Precisamente porque el contenido de un deber positivo es una acción, cuando se presentan dos o más casos en los que ella debe cumplirse, su realización simultánea es fácticamente imposible. Pero esto no altera el carácter de «abierto» («open-ended») de la obligación, sino tan sólo las condiciones de su cumplimiento. Porque ello es así, mientras que la nota de generalidad puede predicarse tanto de las obligaciones negativas como de las positivas, la exigencia de simultaneidad vale para las primeras pero no para las segundas.

En efecto, en el caso de un deber negativo general, por ejemplo, la prohibición de matar, el número de personas protegidas por esta prohibición no altera en nada la posibilidad de su cumplimiento y quien en medio de una muchedumbre no mata a nadie ha cumplido simultáneamente el deber negativo de no matar.

En cambio, si sentado al borde de una piscina veo que tres niños de corta edad caen al agua y corren el peligro inmediato de ahogarse y puedo salvarlos con «un sacrificio trivial», tendré el deber positivo de hacerlo, pero ello no exige que tenga que salvarlos a los tres simultáneamente. Más aún, es probable que tenga que actuar sucesivamente, pero ello no significaría violación alguna de mi deber. Y por supuesto que si en vez de tres niños que caen a la piscina se trata de contribuir a aliviar el hambre de millones de personas, la exigencia de simultaneidad resulta manifiestamente disparatada. 
En este sentido, la exigencia de simultaneidad en el caso de los deberes positivos no es que conduzca a un «dilema» sino que se trata de un requerimiento de cumplimiento imposible que impide hablar de deber.

Si se abandona la exigencia de simultaneidad, se puede pensar -como Fishkin- que el carácter de generalidad de la obligación implica sin embargo el cumplimiento reiterado y sin pausa, suponiendo, además, que la acción que se reitera es siempre la misma ya que si así no fuera, al cambiar el contenido de la obligación se estaría hablando de obligaciones diferentes. La comparación con el grano y el montón o con el pelo que se pierde sucesivamente y la calvicie parece sugerir que Fishkin piensa que un sacrificio trivial reiterado es siempre un sacrificio trivial, de la misma manera que un grano es igual a otro y un pelo que cae igual al perdido anteriormente.

Pero es obvio que tal no es el caso: toda reiteración de una acción en un lapso relativamente breve significa un aumento en la intensidad del esfuerzo requerido para realizarla. Esto hace que el «costo» de las acciones sucesivas no sea nunca igual al de la primera de la serie. El «dilema de Fishkin» se revela aquí como un seudodilema ya que en realidad sólo se puede llegar al límite del heroísmo y a la sobrecarga que destruye la «estructura básica de nuestra moral individual» si se viola el presupuesto del que parte Fishkin, es decir, que el contenido de la obligación es siempre el mismo: un sacrificio trivial. En el «dilema de Fishkin», lo que sucede es que se equiparan obligaciones diferentes: la realización de un sacrificio trivial de costo $\mathrm{c}_{1}$, con sucesivas acciones cuyo costo es $\mathrm{c}_{2}, \mathrm{c}_{3}, \ldots \mathrm{c}_{\mathrm{n}}$. Y que el sacrificio que requiere $\operatorname{costos} c_{2}, c_{3} \ldots c_{n}$ puede no ser ya trivial, es también obvio. El cambio de intensidad de esfuerzo puede conducir al umbral del heroísmo; pero ello no se debe al cumplimiento de la obligación originaria que exigía tan sólo un sacrificio trivial, sino a la realización de actos que han dejado de ser triviales porque sus costos son mayores. Sostener lo contrario es realizar una equiparación falsa: la equiparación entre obligaciones generales y obligaciones ilimitadas. Justamente porque el contenido de las obligaciones son siempre acciones u omisiones, éstas tienen que estar definidas o delimitadas para que tenga sentido imponerlas. No es que el límite de la obligación se vaya desplazando dinámicamente hacia el umbral del heroísmo, como sugiere Fishkin, sino que el límite es estático y sigue siendo el mismo; en este caso, la definición de sacrificio trivial.

Cuando los sacrificios triviales son realizados espaciadamente en el tiempo, es probable que no se produzca un cambio en la intensidad del esfuerzo requerido. Pero para que ello sea así es preciso que se cumpla la condición de recuperación que prescribe la regla b), es decir, que el obligado vuelva a encontrarse en la misma situación en que estaba al realizar el primer sacrificio.

Este mismo efecto puede lograrse si se produce un cambio no sólo en la variable «intensidad de esfuerzo» sino que, simultáneamente con el requerimiento de un mayor esfuerzo, aumentan proporcionalmente las otras variables de la situación del obligado, por ejemplo, la variable recursos. En este caso se habría producido un «cambio de escala» y la reiteración de esfuerzos no provocaría el peligro del «dilema de Fishkin». Las condiciones de la acción contenido de la obligación se mantendrían idénticas y se trataría por lo tanto de la misma obligación. 
El «dilema de Fishkin» no es en verdad tal pues: o bien se produce un «cambio en la intensidad de esfuerzo» y en ese caso se puede llegar al límite del heroísmo pero la prestación debida no es la misma, con lo que desaparece uno de los presupuestos del dilema. O bien se produce un «cambio de escala» y en ese caso la prestación es la misma pero entonces no se llega al límite del heroísmo, con lo que se elimina uno de los cuernos del «dilema» (cfr. Martin C. McGuire 1985, 220).

Resumiendo, puede decirse que la regla b) asegura que estamos hablando siempre del mismo deber positivo general de cumplimiento no simultáneo. Si violamos esta regla comenzamos a deslizarnos por un camino a lo largo del cual se nos van imponiendo obligaciones diferentes cada vez mayores y el deber positivo se transforma en una invitación al heroísmo o en un «masoquismo disfrazado de heroísmo», para usar una expresión de Henry Shue $(1983,272)$.

La regla c) toma en cuenta el hecho de que el individuo obligado no está aislado en el mundo sino que actúa dentro de un grupo para cuyos integrantes rige también la obligación de ayuda. Y es obvio que los costos de la ayuda pueden estar afectados por el comportamiento de cada uno de sus miembros, tanto en sentido positivo (por ejemplo, estímulos para el cumplimiento de la obligación) como negativo (actitud de «polizón» por parte de algunos si el grupo es relativamente grande).

Cuando se trata de obligaciones colectivas y delimitables individualmente (como es, por ejemplo, el caso de la contribución a la lucha contra el hambre en el mundo), nadie está moralmente obligado a realizar más de la parte que le corresponde, aun en el caso de que alguien no cumpla con su parte. Sostener la existencia de un deber abierto de compensar las deficiencias de los demás tendría la fatal consecuencia práctica de que muchos pensarían (con razón) que el mundo no estaría peor si ellos no contribuyeran ya que siempre habría algún otro (igualmente responsable aunque hubiera cumplido ya con su parte) que estaría obligado a compensar sus deficiencias (cfr. Jonathan Cohen 1981, 65-ss.). Y quienes actúan moralmente mal, al no contribuir en la medida exigible, estarían en condiciones de imponer cargas adicionales a quienes cumplen con su deber, conclusión ciertamente inaceptable (John D. Hodson 1983, 69).

La regla d) es una respuesta al conocido argumento de la haraganería formulado por John Locke o a los temores de quienes sustentan un liberalismo extremo y afirman que los únicos deberes universalizables son los negativos ya que la vigencia de los deberes positivos conduciría a una «sociedad irresponsable» en la que «el dinero de los diligentes, los exitosos y los sobrios es dado a los ociosos, a los fracasados y a los insensatos» (Rhodes Boyson 1971, 5).

La regla e) procura evitar las objeciones de Wellman y recoge sugerencias de las asociaciones estructuradas de Robert Nozick. La división del trabajo y el criterio de la especialización contribuyen a disminuir los costos del cumplimiento de los deberes positivos y aumentan la eficacia de la ayuda. En este sentido, el deber positivo de cada cual está también determinado por el deber que corresponde a los demás.

5') Los argumentos vinculados con la distinción entre acción y omi- 
sión no son tampoco buenas razones para rechazar los deberes positivos generales.

Por lo pronto, la intención no constituye una diferencia esencial entre acciones y omisiones. La introducción del elemento intencional como nota distintiva de toda acción trae aparejados graves problemas conceptuales (como, por ejemplo, el de las excusas de las acciones involuntarias), que no he de analizar aquí. Pero, dejando de lado estos problemas, no hay duda que si se compara una acción intencional con una omisión intencional, no existe ninguna diferencia entre ambas por lo que respecta a su reprochabilidad moral. La «apatía» que suele imputarse a quien omite suele ser el resultado de la acción intencional de no querer informarse de las situaciones en las que se requiere el cumplimiento de un deber positivo general. Éstos son los casos que Ted Tonderich llama «omisiones parcialmente intencionales» (1980, 71).

Es falso sostener que la acción es «más causa» del resultado que la omisión. Cuando una omisión completa el contexto de las condiciones necesarias para la producción de un evento y las vuelve suficientes, es tan causa como la acción que inicia la cadena causal. Por otra parte, la vinculación entre responsabilidad causal y responsabilidad moral, que parece estar presente en este argumento, no es aceptable sin más. Se puede ser inadvertidamente la causa de la muerte de una persona, sin por ello ser moralmente responsable (Biellotti 1981, 87). Y puede pensarse también en los casos que Nozick llama «amenazas inocentes», es decir, cuando alguien «es inocentemente agente causal en un proceso tal que hubiera sido un agresor en el caso de que hubiera elegido ser agente de la acción» $(1974,87)$.

Sostener que las omisiones no requieren tiempo y por ello su lista es interminable, es confundir omisión con no hacer. Sólo podemos omitir la acción que podemos realizar. La omisión es la negación interna de la acción. En este sentido, la lista de las omisiones posibles es tan larga como la de las acciones posibles.

Los efectos colaterales de la acción y la omisión, cuando en ambos casos se actúa u omite intencionalmente (o no intencionalmente) no parecen ser muy diferentes. El ejemplo del pulmón artificial de Glover es instructivo al respecto: ¿por qué habría de provocar más escándalo desconectarlo que no conectarlo? La responsabilidad moral de la acción y la omisión es la misma. Cuando se equiparan los elementos de intencionalidad (o no intencionalidad) y de publicidad de la acción y la omisión, no se ve muy bien por qué los efectos colaterales de aquélla tengan necesariamente que ser más graves que los de esta última.

Por cierto que una diferencia fundamental entre acción y omisión es la necesidad de una expectativa empírica o deóntica para que pueda hablarse de omisión. El caso que aquí interesa es el de la expectativa deóntica: la objeción que suele hacerse en contra de la equiparación de deberes positivos y negativos sobre la base de la distinción entre omisión y acción es, en cierto modo, circular: para que pueda hablarse de omisión es necesario haber aceptado antes la existencia de la obligación. Y esto es precisamente lo que niegan quienes recurren al argumento de la diferencia entre la acción y la omisión. Conviene pues considerar los argumentos en favor de la existencia de 
los deberes positivos generales. Si ellos son convincentes, la distinción entre acción y omisión pierde su relevancia, tal como sucede cuando se trata de acciones u omisiones impuestas o prohibidas por deberes negativos o positivos especiales.

\section{II}

La justificación racional de los deberes negativos ha sido siempre tema central de toda ética normativa. No obstante la diversidad de los argumentos formulados a tal fin, todos ellos coinciden, por lo menos, en tres puntos: a) la imposición de estos deberes es necesaria para posibilitar la vida en sociedad; b) todos ellos procuran reducir la interferencia en la esfera individual creando una especie de cerco protector que asegure el mayor desarrollo posible de la autonomía personal y c) estos deberes rigen igualmente para todos y son, por consiguiente, una auténtica expresión del principio básico de universalización. Dicho de otra manera: a través del respeto de la libertad y la igualdad, aseguran óptimamente la existencia humana.

Quienes se oponen a la imposición de deberes positivos generales suelen aducir que su intento de justificación viola el principio de libertad y/o igualdad y que, además, no son deberes indispensables para la convivencia humana.

La primera objeción tiene una formulación precisa en la frase expresada en 1928 por el juez Brandeis, de la Suprema Corte de los Estados Unidos: «El derecho que más aprecia toda persona civilizada es el derecho a que la dejen tranquila». La no interferencia es condición necesaria de la tolerancia -reza una versión actual de esta tesis- razón por la cual la imposición de deberes positivos, tal como lo pretende el Estado social, viola uno de los principios básicos de la democracia liberal. La única buena razón para justificar la existencia del Estado, se dice, es aquélla que demuestra que el Estado está en condiciones de proteger los derechos negativos de sus ciudadanos asegurando una paz pública que permite a cada cual organizar su vida como le plazca. Y la mano invisible de la que hablaba Adam Smith hará que el cultivo del interés privado produzca la felicidad pública. Seres racionales estarán dispuestos a crear un Estado que garantice la vigencia de los deberes negativos ya que ello significa una economía de los costos que implica la autodefensa; pero no apoyarán la instalación de una autoridad que imponga deberes positivos y la vigencia de los correspondientes derechos positivos «porque tal autoridad no conseguiría un ahorro comparable de costo en el esfuerzo requerido para asegurar bienes positivos» (Michael Levin 1984, 94). Más aún: «Por cada persona que recibe un dinero sin habérselo ganado, hay otra que, habiéndoselo ganado, no lo ha recibido. Un gobierno puede legalizar el robo pero no justificarlo» (declaraciones de un ex-senador de Louisiana reproducidas por el semanario Die Zeit $\mathrm{N}^{\mathrm{o}}$ 8/1985, 35). Hay que distinguir, se dice, entre la «igualdad ante la ley» y la «igualdad del resultado». Sólo la primera es moralmente justificable; la segunda, cuando significa la intervención del Estado para equilibrar desigualdades, es inconciliable con la libertad. 
Cuesta realmente entender esta tesis que, al vincular conceptualmente la tolerancia con la no interferencia, nos sugiere la conclusión de que el levita en el camino de Jericó es más tolerante que el buen samaritano y, en este sentido, un mejor candidato para una sociedad democrática. Pero, desde luego, no basta afirmar que una tesis es de difícil comprensión para inferir de allí su falsedad. Lo relevante en este caso es que si se niega la posibilidad de interferencia en el comportamiento humano en aras de un máximo de tolerancia, no se ve por qué deban aceptarse ni siquiera los deberes negativos. También ellos limitan la libertad de acción y tienden a crear una «igualdad de resultado», haciendo que el débil sea igual que el fuerte y castigando a quien desee elegir su propia vía de acción con total libertad y prescindiendo de los intereses de los demás. El problema del «tonto» del que hablaba Hobbes, que no comprende las ventajas de las limitaciones del uso de la violencia, o del «outsider» de Nozick, que no quiere pagar su póliza en la asociación protectora, es insoluble si la decisión última depende de la libre voluntad del obligado y no del reconocimiento de un bien digno de ser protegido. Que algunas versiones del liberalismo extremo se rozan con el anarquismo es cosa bien sabida, desde William Godwin hasta el neoconservadurismo norteamericano de nuestros días representado, entre otros, por Benjamin Hart y Charles Murray: «Al igual que la izquierda de los años sesenta, nosotros exigimos: ¡destruid el Estado!» (Hart en Die Zeit loc. cit.). Pero la cuestión es saber si un liberal coherente, que acepte la necesidad de proteger la autonomía individual y los bienes primarios que permiten su desenvolvimiento, puede darse por satisfecho con la mera imposición de deberes negativos. Sobre este punto volveré en III. Aquí conviene sólo retener que el argumento de la no interferencia, tomado estrictamente, tendría que valer también para los deberes negativos y entonces o se cree en la posibilidad de un angélico anarquismo o se adopta la posición del «tonto» o del «outsider». Probablemente esta alternativa no será atractiva para quien se niega a aceptar los deberes positivos generales; en este caso tendrá que admitir que el argumento de la no interferencia no ofrece buenas razones para sostener que la fundamentación de los deberes positivos es diferente a la de los negativos.

$\mathrm{El}$ argumento de la igualdad sostiene que los derechos positivos no pueden ser compartidos igualmente por todos. Su ejercicio igualitario conduce a su autodestrucción. Si cada cual, por ejemplo, tiene un derecho fundamental a la subsistencia, ello significaría que cada cual puede no hacer nada y sin embargo, exigir alimentos: la igualdad en el ejercicio de este derecho conduce a su aniquilamiento.

Michael Levin (1984) ha expuesto claramente esta tesis. Su punto central es que los derechos positivos (contrapartida de los deberes positivos) o bien son universalizables y entonces al poseerlos todos no los puede gozar nadie, o bien están reservados a determinados grupos y por lo tanto no son universalizables:

«Sólo los derechos negativos pueden ser universales e incondicionados... Derechos tales como los de la libertad de expresión son conspicuamente incondicionados: las garantías de no interferencia con respecto al derecho de libre expresión no están pensadas de manera tal que sólo se apliquen a ciudadanos que satisfacen alguna condición adicional . . . los de- 
rechos positivos al producto social tienen que estar limitados a algún segmento de la población...» $(1984,91)$.

Este argumento padece de una confusión básica que resulta de creer que el principio de universalización implica la eliminación de toda distinción entre diferentes clases de obligados y de derecho habientes, ya que toda «segmentación» significaría privilegiar a un grupo o a una clase de personas. Las consecuencias de esta implicación son por cierto inquietantes: el deber de imparcialidad, que está impuesto al «segmento» de los jueces, no podría ser fundamentado moralmente porque no es universalizable de forma tal que sea aplicable a todos los seres humanos en todas las situaciones (basta pensar en los deberes de la amistad y su relación con la imparcialidad). Creer que universalización significa la eliminación de toda distinción entre los agentes morales es confundir universalización con incondicionalidad y establecer un igualitarismo que sí destruye la posibilidad de vigencia de preceptos generales.

Al juez Brandeis se le podría responder con Leibniz:

«Alguien puede decir: Yo me contento con que los otros no me dañen, no les pido su ayuda y tampoco quiero hacer ni pedir más. Pero, ¿es posible sostener este lenguaje sinceramente? Que él mismo se pregunte qué diría y esperaría si él mismo se encontrara a punto de caer en un mal y alguien pudiera salvarlo con sólo mover su mano. ¿No consideraría que es un malvado y hasta su enemigo si no quisiera salvarlo en esta ocasión?» $(1893,55)$.

La imposibilidad de «sostener sinceramente» la obligación de no dañar y rechazar al mismo tiempo el deber de asistencia encontró su formulación clásica en Kant:

«... alguien a quien le va bien, ve que otros tienen que luchar con grandes dificultades (y a quienes podría ayudar): ¿qué me importa esto a mí? Que cualquiera sea tan feliz como el Cielo lo quiera o como él mismo pueda lograrlo, no le quitaré nada, ni siquiera lo envidiaré; pero con respecto a su bienestar, a prestarle ayuda en su penuria, no tengo ganas de contribuir en algo... A pesar de que es posible que pudiera existir una ley general de acuerdo con esta máxima, es imposible querer que una tal ley natural valga siempre. Pues una voluntad que dispusiera esto se contradiría a sí misma en los casos ... en los que necesita del afecto y de la solidaridad de otros y en los cuales, en virtud de la ley natural surgida de su propia voluntad, se privaría a él mismo de toda esperanza de la ayuda que él mismo desea» $\left(1956^{1}, 54\right)$.

Por supuesto que puede darse el caso de que alguien tenga una fuerza de voluntad tal que, aun estando en situación de penuria, no requiera la ayuda de otros, precisamente para no entrar en contradicción con la máxima que él mismo sostiene, es decir, permanecer indiferente frente a la penuria de los demás. Esta situación es similar a la de quien rechaza la existencia de deberes negativos, por ejemplo, la prohibición de matar, porque se considera lo suficientemente fuerte como para resistir el peligro de ser muerto y no quiere privarse de la libertad de matar. Esto nos vuelve nuevamente a plantear el caso del «tonto» o del «outsider» y pone de manifiesto dos cosas: a) los mismos argumentos valen para la aceptación o rechazo de los deberes negativos y positivos; b) una fundamentación de los deberes morales basada exclusivamente en el interés individual no nos libera del problema del «ton- 
to», del «outsider» o del «fanático». El punto a) confirma la tesis aquí sostenida y b) sugiere la conveniencia de no reducir la fundamentación de las normas éticas a la consideración de razones estratégicas sino a buscartambién en los casos en que se recurra a una racionalidad consensual- un apoyo en el reconocimiento de derechos que son considerados como bienes necesarios, no susceptibles de ser recortados de acuerdo con las preferencias individuales del agente (cfr. Gewirth 1978, 164, s.).

Si se acepta que los deberes negativos son impuestos para la protección de bienes necesarios que no deben ser dañados y se está también de acuerdo en que no prestar ayuda a quien se encuentra en situación de penuria es infringirle un daño que permite calificar de «enemigo» a quien así actúa, es también obvio que las razones que valen para la implantación de los deberes negativos valen también para los positivos. Esto es lo que Leibniz llamaba el principio de equidad, es decir, de identidad o igualdad de razones. La negación de este principio conduce a una fatal contradicción.

Pero, si son las mismas razones las que rigen para los deberes negativos y para los positivos, podría concluirse que se trata tan sólo de un único deber: el deber de no dañar, que posee una versión positiva y otra negativa. Ésta es la propuesta de John Harris $(1980,60)$ :

«Tenemos el deber de no dañar a nadie omitiendo acciones que si se hubieran realizado hubieran evitado el daño. Éste sería el modo pasivo del mismo deber que en modo activo puede ser expresado como el deber de no dañar a nadie realizando acciones perjudiciales, cuya realización podría haber sido evitada.»

La sugerencia es sin duda atractiva, pero su aceptación significaría desconocer que entre los deberes negativos y los positivos existen las asimetrías señaladas más arriba: aunque el objetivo perseguido con la implantación de los deberes positivos es el mismo que el de los deberes negativos, es decir, no dañar bienes necesarios, las prestaciones de ambos tipos de deberes son diferentes y conviene por ello mantener su distinción.

Que la existencia de deberes negativos generales es necesaria para posibilitar la vida en sociedad es algo que no requiere aquí mayor explicación; lo que me importa en cambio es saber si son suficientes para lograr este fin. Aunque de lo hasta ahora expuesto es obvio que la respuesta a esta cuestión habrá de ser negativa, conviene detenerse brevemente en su consideración. A ella está dedicada la sección siguiente.

\section{III}

«No es la existencia de un deber lo que hace que la muerte de quien se está ahogando sea una consecuencia de que no le hayamos prestado auxilio sino que es más bien el hecho que, a menos que lo auxiliemos morirá, lo que hace que auxiliarlo sea nuestro deber.»

Esta frase de John Harris $(1980,31)$ pienso que es adecuada para poner el acento en el objetivo central de una ética normativa. Los deberes que ella impone -sean negativos o positivos- no constituyen un fin en sí mismos sino que tienen un carácter eminentemente instrumental, es decir, asegurar la protección de bienes que se consideran valiosos. Por ello es que la ética 
no es un lujo o un ejercicio más o menos ingenioso de los filósofos sino un conjunto de reglas con fines pragmáticos.

La existencia de deberes negativos generales es una de las características del llamado «estado de naturaleza» en su versión lockeana, cuya superación es el punto de partida de la justificación del Estado liberal. El objetivo de esta superación era la eliminación de la inseguridad social provocada principalmente por la vulnerabilidad humana, el altruismo limitado, la igualdad aproximada, la comprensión y fuerza de voluntad limitadas y la limitación de recursos (cfr. H. L. A. Hart 1961, 190 ss.). La propuesta de solución fue la institucionalización de deberes positivos especiales reducidos a las funciones de la policía y del juez. Hasta qué punto esta vía fue insuficiente lo demuestra la historia de las crisis del Estado liberal en su versión restringida de conjunción de deberes negativos generales y deberes positivos especiales. La necesidad de ampliar el campo de los deberes positivos especiales dio origen así al Estado social de derecho.

Pero así como en el plano de la moral individual la creación del Estado lockeano no eximía de la obligación de cumplir los deberes negativos generales, tampoco el establecimiento del Estado social exime de la obligación de cumplir con los deberes positivos generales, cuya justificación es la misma que la de los deberes negativos generales: la protección de bienes que se consideran valiosos. La clase de estos bienes está definida por criterios de coherencia y de equidad; es decir, no es posible excluir de ella arbitrariamente bienes que poseen las características definitorias para ser sus miembros. John Rawls ha acuñado la feliz expresión «bienes primarios» y Peter Singer ha introducido en la ética la idea del «círculo en expansión».

El concepto de Rawls hace referencia a aquEllos bienes que son necesarios para la realización de cualquier plan de vida; desde este punto de vista, no es posible incluir en su clase tan sólo a la vida y la seguridad de la propiedad e ignorar que sin recursos para la subsistencia la vida misma resulta imposible. La idea de Singer nos pone de manifiesto que si se acepta el punto de vista moral, no es posible quedarse a medio camino retaceando el reconocimiento de bienes primarios sino que hay que aceptar la tendencia a una creciente protección de las necesidades humanas si es que se quiere aplicar coherentemente los principios morales de la imparcialidad, la universabilidad y el respeto por la autonomía personal.

En la tradición europea del liberalismo, esta vía comenzó a recorrerse con el reconocimiento de la necesidad de proteger al físicamente más débil y ahorrar los costos de la autodefensa. Que la debilidad de los integrantes de un grupo social puede ser no sólo física es cosa harto sabida y que existen sociedades en las cuales la insatisfacción de necesidades vitales es tan grande que ni siquiera tiene sentido comenzar a hablar de la justicia, como diría Rawls, también. La misma idea de protección al «débil» y su equiparación al «fuerte» exige por ello un refuerzo de los deberes positivos de asistencia. Ello aumenta por cierto la clase de las omisiones moralmente reprochables pero no nos lleva al «dilema de Fishkin» ni nos hace responsables por todos los males que ocurran en el mundo. El reconocimiento de deberes positivos generales no significa tampoco la autodestrucción de los obligados ni es la etapa previa al «trágico evento» de la pauperización general que preveía T. R. 
Malthus (1800, 17 s.). El límite del «sacrificio trivial» impide que ello se produzca. Si esto es así, la coherencia liberal parece exigir la aceptación de lo que ha sido llamado el «Estado social de derecho». Pero éste es un tema que escapa a los límites de este trabajo y que apunta al problema de la legitimidad de las instituciones sociales. Aquí tan sólo quería referirme a la justificación moral de los deberes positivos generales en las relaciones interpersonales.

\section{BIBLIOGRAFÍA}

Belliotti, Raymond A. (1981): «Negative and Positive Duties» en Theoria vol. XLVII, Part 2.

Boyson, Rhodes (ed) (1971): Down with the Poor, Londres

Brennan, Geoffrey y Loren Lomansky (1984): «Inefficient Unanimity» en Journal of Applied Philosophy, vol 1, N. ${ }^{\circ} 1$.

Cohen, Jonathan (1981): «Who is starving whom?» en Theoria, vol. XLVII. part 2.

Collins, Joseph y Frances Moore Lappé (1977): Food First - Beyond the Myth of Scarcity, San Francisco.

Feinberg, Joel (1983): «The Moral and Legal Responsibility of the Bad Samaritan, ponencia presentada en el 11 Congreso Mundial de Filosofía del Derecho y Filosofía Social, Helsinki.

Feinberg, Joel $\left(1983^{2}\right)$ : «Legal Paternalism» en Rolf Sartorius (comp.), Paternalism, University of Minnesota.

Fishkin James S. (1982): The limits of Obligation, New Haven.

Fletcher, Josef (1976): «Feeding the Hungry: An Ethical Appraisal» en George R. Lucas (ed.), Lifeboat Ethics. Nueva York.

Gewirth, Alan (1978): Reason and Morality, Chicago.

Glover, Jonathan (1977): Causing Death and Saving Lives, Londres.

Hardin ,Garret (1976): «Carrying Capacity as an Ethical Concept» en George R. Lucas (ed.), Lifeboat Ethics, Nueva York

Harris John (1980): Violence and Responsibility, Londres

Hart, H. L. A. (1961): The Concept of Law, Oxford.

Hodson John D. (1983): The Ethics of Legal Coertion, Londres

Honderich, Ted (1980): Violence for Equality, Suffolk

Kant, I. (1956 ${ }^{1}$ ): Grundlegungung Metaphysik der Sitten $\left(1956^{2}\right)$ : Die Metaphysik der Sitten en Werke (edición a cargo de Wilhelm Weischedel), tomo IV, Darmstadt

Leibniz. G. W. (1893): «Méditation sur la notion commune de la justice» en G. Mollat (ed.), Mitteilungen aus Leibnizens ungedrückten Schriften, Leipzig

Levin, Michael (1984): «Negative Liberty» en Social Philosophy and Policy, vol. 2, I.

Malthus, T. R. (1800): An Investigation of the Cause of the Present High Price of Provisions, Londres

MacGuire, Martin C. (1985): «The Calculus of Moral Obligation» en Ethics, vol. 95, N. ${ }^{\circ} 2$

Murphy, Jeffrie (1979): Retribution, Justice and Therapy, Londres

Nozick, Robert (1974): Anarchy, State and Utopia, Cambridge

Shue, Henry (1983): «The Limits of Obligation» en Political Theory, vol. 11, N. ${ }^{o} 2$.

Ross, W. D. (1963): The Right and the Good, Oxford.

Sen, Amartya (1982): Poverty and Famines - An Essay on Entitlement and Deprivation, Oxford.

Singer, Peter (1979): Practical Ethics, Cambridge.

Trammell, Richard L. (1975): «Saving Life and taking life» en Journal of philosophy, vol. 72.

Trammell, Richard L. (1976): «Tooley's moral symmetry principle» en Philosophy and public affairs, vol. 5 .

Wellman, Carl (1982): Welfare Rights, Totowa, New Jersey.

Wright, Georg H. von (1963): The Varieties of Goodness, Londres.

DOXA 3 (1986) 